\title{
PERSPECTIVE
}

GLOBAL HEALTH

\section{Achieving the Millennium Development Goals - The Case of Malaria}

\author{
Jeffrey D. Sachs, Ph.D.
}

Malaria currently kills up to 3 million people per year worldwide, most of them children in sub-Saharan Africa. ${ }^{1}$ Yet the disease is utterly treatable and highly preventable. Now, the international community has vowed as part of its Millennium Development Goals to make appropriate investments and interventions to bring this scourge under control. These goals, adopted by world leaders at the United Nations Millennium Assembly in September 2000, represent a commitment to reducing extreme poverty and diseases such as malaria sharply by 2015 . Among other objectives, the eight development goals call for reducing by half the rates of extreme poverty and hunger by 2015 and reducing childhood mortality by two thirds and maternal mortality by three fourths relative to their 1990 levels. The goals also target the control of the great pandemic diseases - human immunodeficiency virus (HIV) and AIDS, tuberculosis, and malaria. In 2002, the highincome countries, including the United States, made a commitment to substantially increasing their aid to poor countries in order to meet these ambitious but achievable targets, though the actual flow of aid has not yet increased markedly.

Three years ago, I was asked by U.N. SecretaryGeneral Kofi Annan to direct a worldwide effort to identify practical means for achieving the Millennium Development Goals in all countries that sought to do so. The U.N. Millennium Project recruited a global network of experts and leading practition-

Dr. Sachs is the director of the Earth Institute at Columbia University, New York, the director of the United Nations Millennium Project, and Special Advisor to U.N. Secretary-General Kofi Annan on the Millennium Development Goals. ers from many key disciplines to identify a practical course of action. Our final report, Investing in Development: A Practical Plan to Achieve the Millennium Development Goals, as well as final reports of 10 task forces, were presented to Secretary-General Annan on January 17, 2005. Our central conclusion is that the goals can indeed be met through well-designed and concerted actions, but they will not be met in large areas of the world if we continue with business as usual. The current international system of development assistance is not functioning properly. There is too little aid, and it is too poorly directed to enable the world's poorest countries to invest ambitiously in disease control and poverty reduction. The situation is most dire in sub-Saharan Africa.

More specifically, we found that poverty reduction and disease control are amenable to targeted investments using proven and effective technologies. Extreme poverty can be cut sharply in a decade's time by scaling up investments in key infrastructure (such as roads, power, water, and sanitation) and human capital (such as education, nutrition, health care, and family planning). Such investments would not only improve living conditions by 2015 , but would also help the poorest countries to achieve sustained economic growth after that date. The central problem, however, is that the poorest of the poor are caught in a "poverty trap" from which they are unable to mobilize the resources to make the investments required for economic growth; the result is a vicious circle of poverty, ill health, and chronic hunger. Rapid increases in population exacerbate the underlying problems.

The key to breaking the poverty trap is increased assistance from rich countries to enable the poorest countries to put the basic infrastructure and hu- 
man capital in place. This means increased donor funding to help fight disease, establish a network of primary health care posts, improve and extend schooling, and build the networks of roads, power, and telecommunications on which a modern economy depends. The cost of these basic investments is low enough that donors could provide the needed sums with about 0.5 percent of their combined income -50 cents per $\$ 100$ of income, or roughly $\$ 150$ billion per year from the high-income countries with a combined annual income of $\$ 30$ trillion.

We also found that there are several critical areas in which "quick wins" are possible - problem areas where very modest investments could lead to enormous breakthroughs in human well-being and economic development. Such dramatic results are familiar from the global experience with donorbacked immunization campaigns, but most policymakers are unaware that similar benefits can be achieved in other areas of health care and poverty reduction. The scientists and development experts involved in the U.N. Millennium Project identified dramatic and quick gains to be achieved in controlling malaria, AIDS, tuberculosis, and other diseases; food production; school attendance and performance; and many other vital areas.

One goal that is clearly within reach is a breakthrough in malaria control in Africa. Given tropical Africa's unique disease ecology (which combines high temperatures, favorable breeding conditions for mosquitoes, and species of anopheles mosquitoes with a high propensity for biting humans), the intensity of malaria transmission and the magni-

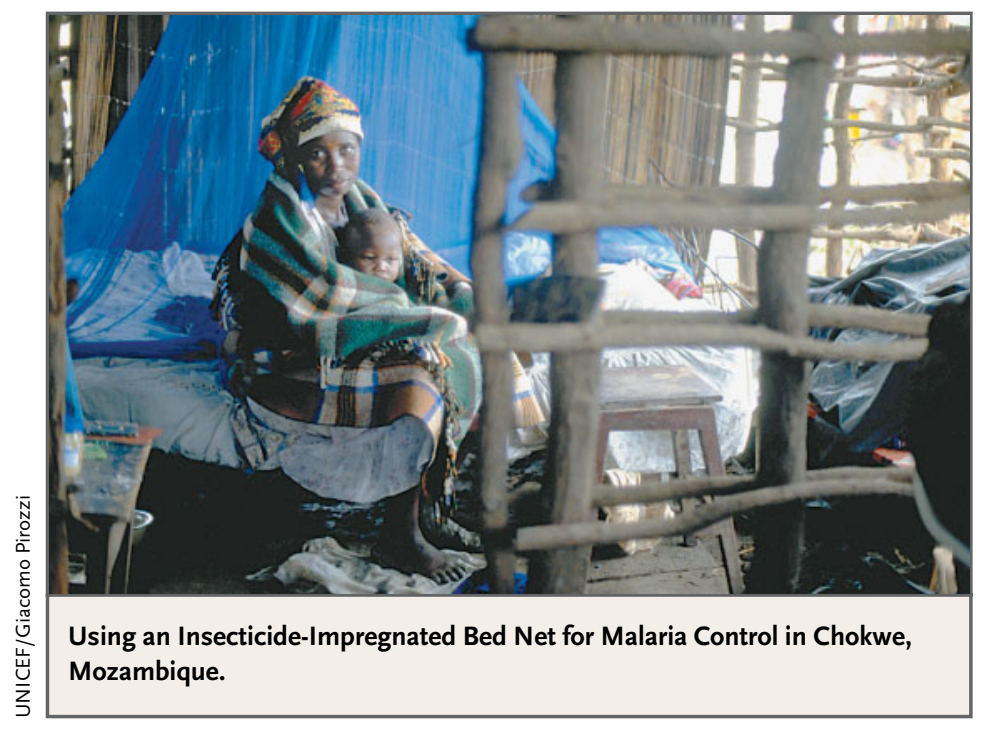

tude of the resulting disease burden is unrivaled in the world. ${ }^{2}$ The situation has worsened markedly in the past decade, with the spread of malaria parasites that are resistant to first-line drugs such as chloroquine and the breakdown of basic public health systems in the face of unrelenting poverty, the HIV-AIDS pandemic, and civil conflict.

Despite malaria's shocking toll in illness, lives, and economic costs, ${ }^{3}$ investments in malaria control have been remarkably low, hovering around a paltry $\$ 100$ million to $\$ 200$ million per year from all international donors. ${ }^{4}$ The UN Millennium Project's Working Group on Malaria, headed by Prof. Burton Singer of Princeton University and Prof. Awash Teklehaimonot of Columbia University, found that $\$ 2$ billion to $\$ 3$ billion each year is in fact needed to enable poor African countries to achieve substantial control over the disease. The required annual investment would amount to a mere $\$ 2$ to $\$ 3$ for each of the roughly 1 billion people in the developed world. These sums are therefore tiny for rich countries, but they are out of reach for the impoverished people and governments in the subSaharan Africa's malarious regions.

A scaled-up control effort would include the free distribution of bed nets and effective medicines to impoverished rural Africans, who cannot afford to buy the nets even at highly subsidized prices. In repeated trials in villages in Africa, insecticide-impregnated bed nets have proved highly effective in reducing morbidity and mortality, especially when an entire village uses the nets and thereby reaps the benefit of mass community effects. ${ }^{5}$ Communitybased health workers can be trained to help villagers in using the nets properly. And even hard-boiled cynics would agree that bed nets are not likely to end up in offshore bank accounts, as can happen with cash assistance. (In fact, the UN Millennium Project underscores the need to target increased financial support to those countries with adequate governance, monitoring, and evaluation, to avoid massive abuse).

Our report calls for urgent action. In the case of bed nets and access to effective medications, my own preliminary soundings suggest that several government donors, the World Bank, the World Health Organization, the Global Fund to Fight AIDS, Tuberculosis, and Malaria, and many private business leaders and philanthropists are prepared to answer the call for a great increase in concerted action. Within three years, virtually every household in the regions of rural Africa where malaria is en-

N ENGL J MED 352;2 WWW.NEJM.ORG JANUARY 13, 2005 
demic could be sleeping under insecticide-treated nets and could have greatly improved access to medications and other appropriate modes of vector control.

The Millennium Development Goals derive their potential power from being clear, bold, measurable, and shared international goals. Achieving them would not only alleviate suffering and promote economic development but also contribute to global security, since poverty and disease are key factors in the collapse of states and the onset of violent conflicts. The U.N. Millennium Project has identified practical means for achieving these goals. Now it is important that the governments of the United
States and other high-income countries follow through on their own commitments to reducing poverty. The results could well be dramatic.

1. Breman JG, Alilio MS, Mills A. Conquering the intolerable burden of malaria: what's new, what's needed: a summary. Am J Trop Med Hyg 2004;71:suppl:1-15.

2. Kiszewski A, Mellinger A, Spielman A, Malaney P, Sachs SE, Sachs JD. A global index representing the stability of malaria transmission. Am J Trop Med Hyg 2004;70:486-98.

3. Sachs JD, Malaney P. The economic and social burden of malaria. Nature 2002;415:680-5.

4. Narasimhan $\mathrm{V}$, Attaran A. Roll back malaria? The scarcity of international aid for malaria control. Malaria J 2004;2:8.

5. Curtis C, Maxwell C, Lemnge M, et al. Scaling-up coverage with insecticide-treated nets against malaria in Africa: who should pay? Lancet Infect Dis 2003;3:304-7.

BECOMING A PHYSICIAN

\section{Mortgaging Our Future - The Cost of Medical Education}

Gail Morrison, M.D.

The cost of obtaining a medical education has been spiraling upward for the past 20 years. Despite a lot of rhetoric in articles ${ }^{1,2}$ and at meetings of the Association of American Medical Colleges, nothing has happened to change the alarming pattern. The average tuition and fees at public medical schools during the 2003-2004 academic year amounted to $\$ 16,153$, and the corresponding figure for private schools was $\$ 32,588$. $^{3}$ Adding $\$ 20,000$ to $\$ 25,000$ for living expenses, books, and equipment brings the estimated cost of four years of attendance to about $\$ 140,000$ for public schools and $\$ 225,000$ for private schools.

The continuing increases in tuition are the primary reason why a medical education is less affordable today than it was two decades ago. In the 1984-1985 academic year, average tuition and fees were $\$ 3,877$ at public medical schools and $\$ 12,973$ at private schools. Thus, in 19 years, the costs increased by 317 percent and 151 percent, respectively (see graph). ${ }^{3}$ Despite low inflation during the past several years, this escalation continued. Recent shortfalls in state budgets have caused major budget crises at most public medical schools, resulting in a need for marked increases in tuition, which went up by 11.9 percent in 2003 and 17.7 percent

Dr. Morrison is the Vice Dean for Education, University of Pennsylvania School of Medicine, Philadelphia. in 2004. Private medical schools, though not as reliant on state money, raised tuition by 4.4 percent in 2003 and 5.7 percent in 2004 - increases well above the rate of inflation.

Accompanying this continuing escalation, there has been an enormous increase in the average indebtedness of graduating students. The average debt carried by 1984 graduates was $\$ 22,000$ for public school and $\$ 26,500$ for private school. By 2004 , the debt had increased to $\$ 105,000$ for public school and $\$ 140,000$ for private school, and only about 20 percent of medical students graduated with no debt. ${ }^{4}$

Although the consumer price index is less than twice what it was 20 years ago, medical-student debt was 4.5 times as high in 2003 as it was in 1984. Tuition, however, has increased at only 2.7 times the rate of the consumer price index at private medical schools and at 3.8 times that rate at public schools. The greater increase in student debt suggests that medical students have chosen to borrow money not only for tuition but also for other costs associated with attending medical school. Since more students now live in apartments rather than dormitories, are married or marry during medical school, have children, need to buy cars for travel to affiliated hospitals and outpatient facilities, and buy computers and other electronic equipment, these other costs have increased dramatically. Most students, even if they come from affluent families, prefer to take out low- 